\title{
Experience from the Implementation of Psychotherapy Interventions in Health Professionals in a Covid-19 Reference Hospital
}

\author{
D Lekka ${ }^{1 *}$ and ME Galanaki ${ }^{2}$ \\ ${ }^{1}$ Department of Psychiatry, Psychologist-Psychotherapist, MSc, PhD (c), Sotiria General Hospital, Greece \\ ${ }^{2}$ Department of Psychiatry, Specialist Psychiatrist, Sotiria General Hospital, Greece
}

*Corresponding author: D Lekka, Department of Psychiatry, Psychologist-Psychotherapist MSc, PhD(c), Sotiria General Hospital, Greece

\section{ARTICLE INFO \\ Received: 亚October 29, 2020 \\ Published: 蔧 November 11, 2020}

Citation: D Lekka, ME Galanaki. Experience from the Implementation of Psychotherapy Interventions in Health Professionals in a Covid-19 Reference Hospital. Biomed J Sci \& Tech Res 31(5)2020. BJSTR. MS.ID.005165.

\section{ABSTRACT}

Introduction: The covid-19 pandemic is a phenomenon that has found society, political systems and health systems around the world unprepared, causing mental health issues to health professionals in addition to its socio-economic impact.

Purpose: working with health professionals consists of identifying, investigating, and intervening early in mental health issues.

Method: from April - June 2020, six groups of eight health professionals were formed, 5 with nursing staff and 1 with doctors. Psychotherapeutic techniques from systemic psychotherapy were used.

Results: the issues that arose were fear, anxiety, stigma, insomnia, anger. With the use of psychotherapeutic techniques, we tried to make sense of what is happening, to bring to the surface the positive emotions and successful ways of dealing with crises as well as what is important to everyone in this life.

Conclusion: The covid-19 pandemic has affected the quality of life of health professionals. Psychotherapeutic interventions are needed to enhance mental resilience and optimism.

\section{Mini Review}

The covid-19 pandemic is a phenomenon that has found society, political systems and health systems around the world unprepared, causing mental health issues for health professionals in addition to its socio-economic impact. Professionals working in hospitals designated for COVID-19 treatment experience a feeling of intense psychological pressure. The high risk of infection, insufficient protection against infection, increased workload, discrimination, isolation, uncertainty about the results of the pandemic, are expected to put stress on health workers, seriously affecting mental health [1]. According to previous studies, the appearance of a sudden life-threatening illness could lead to extraordinary pressures on health professionals. High-intensity work, physical and emotional exhaustion, inadequate personal protective equipment, risk of serious infection during hospitalization, weakness, fear, anxiety and worry for patients and family members and the need to understand the morally demanding decisions that can be made have a dramatic effect on the physical and mental well-being of health professionals. Their resilience can be further jeopardized by isolation and loss of social support, the risk of transmission and infection of friends and relatives, and drastic, often disturbing changes in working conditions. Healthcare personnel, especially those working in the front line during viral outbreaks, are at high risk of developing mental health problems such as anxiety, depressive symptoms, anger, insomnia, fear and sleep disorders [2,3].

\section{Purpose}

In their work with staff groups therapists aimed at identifying, investigating and early intervention in mental health issues. 


\section{Method}

The two therapists, after first obtaining permission from hospital authorities, visited all the nursing wards and formed six groups of eight staff each. Five of these were with nursing staff and one with pulmonologists. The age of the participants was 30-60 years. Two of the groups were with ICU staff and the rest from pulmonology clinics. The duration of the interventions was from April to June 2020, lasting 1.5 hours on a weekly basis with a fixed day and time in the nursing wards. Participants were initially reluctant to speak, but by using circular questions they began to reveal difficult emotions such as fear and anxiety, insomnia, referring to their weight gain and physical discomfort, lack of social contact and stigmatization by relatives as well as people from their wider social environment because they worked in a reference hospital. In particular, a nurse said that a food store owner would not allow her to enter the store and asked her to wait outside for him to bring her groceries, while a doctor said that a person close to her would not meet with her while she works at the hospital. On the other hand, the portrayal of the staff as heroes by the press creates additional stress and pressure to live up to expectations. The moral 'trauma' of the medical and nursing staff is caused when, in the end, the experience and the means applied do not work, and people from all walks of life are seriously affected. Issues arose as to how to adequately distribute care to patients, how to balance their own physical and mental health with that of patients, whether to meet the needs of patients and their families, and how to treat seriously ill patients with inadequate means [4].

ISSN: 2574-1241

DOI: 10.26717/BJSTR.2020.31.005165

D Lekka. Biomed J Sci \& Tech Res

(C) This work is licensed under Creative

Submission Link: https://biomedres.us/submit-manuscript.php
Using positive reframing healthy mechanisms emerge, such as humor and optimism. Groups are given the opportunity to chat with members, to redefine their ties, but also the position and function of each within the group. Non-defined fear and anxiety become the basis for redefining belief in moral values, regulatory principles and virtues that express human dignity and solidarity.

\section{Conclusion}

The covid-19 pandemic has affected the quality of life of health professionals and they need psychotherapeutic interventions to enhance their mental resilience and optimism about what is important in life. Short-term psychotherapeutic interventions have helped to reduce their negative emotions, to recall effective ways of dealing with crises and to acquire effective communication skills.

\section{References}

1. Liu Z, Han B, Jiang R, Hunag Y, Wen J, et al. (2020) Mental Health Status of Doctors and Nurses During COVID-19 Epidemic in China. SSRN Electron J, Lancet.

2. Pappa S, Ntella V, Giannakas T, Giannakoulis V, Papoutsi E, et al. (2020) Prevalence of Depression, Anxiety, and Insomnia Among Healthcare Workers During the COVID-19 Pandemic: A Systematic Review and Meta-Analysis. Brain Behav Immun 88: 901-907.

3. Tselebis A, Lekka D, Sikaras C, Tsomaka E, Tassopoulos A, et al. (2020) Insomnia, Perceived Stress, and Family Support among Nursing Staff during the Pandemic Crisis. Healthcare 8(4).

4. Greenberg N, Docherty M, Gnanapragasam S, Simon Wessely S (2020) Managing mental health challenges faced by healthcare workers during covid-19 pandemic. BMJ 368.

$\begin{array}{ll}\text { BIOMEDICAL } & \text { Assets of Publishing with us } \\ \text { RESEARCHES } & \text { - Global archiving of articles } \\ & \text { - Immediate, unrestricted online access } \\ & \text { - Rigorous Peer Review Process } \\ & \end{array}$

